walt have shown, cells of this strain, after exposure to ultraviolet irradiation, support extensive DNA repair synthesis and they therefore offer an opportunity of comparing the effects of HPUra on repair and replication. In an elegant series of experiments Brown has shown that although the semiconservative replication of the chromosome of this strain is blocked by HPUra, the repair of DNA damage caused by the ultraviolet irradiation continues unabated. For example, he labelled the DNA made after irradiation and in the presence of the drug with radioactive bromo-deoxyuridine and then analysed it on caesium chloride and alkaline gradients. The bulk of the labelled DNA turned up in short chains covalently linked to the parental DNA. Moreover the synthesis of this DNA was greatest in cells given the highest doses of irradiation, and it was inhibited by inhibitors of excision repair synthesis such as actinomycin D.

Because Brown found last year that the replication of virulent phages in $B$. subtilis is not blocked by HPUra he was at pains to eliminate the possibility that the synthesis of DNA in irradiated cells, which is insensitive to HPUra, is nothing more than the replication of a defective prophage induced by the irradiation. The properties of defective B. subtilis prophages make this idea implausible and furthermore he has shown, first, that synthesis of DNA in irradiated cells does not immediately depend on protein synthesis and, second, that mitomycin $\mathrm{C}$ treatment, which like irradiation induces defective prophages of $B$. subtilis, does not induce an HPUra-refractory DNA synthesis. In short, there seems little doubt that it is the repair of irradiation damage that continues in the presence of HPUra.

If HPUra is as selective an inhibitor of DNA semiconservative replication as Brown's work indicates it should prove an extremely useful tool for identifying the real DNA replicase. But Brown's claim that DNA synthesis in toluenized cells continues in the presence of this drug (and unfortunately he has not yet published the detailed evidence on which he rests this assertion) must come as a blow to cell biologists who have pinned their hopes on toluenized cells as a system for investigating DNA replication in vitro. The experiments reported by Sueoka's group in Nature New Biology $(232,111 ; 1971)$, for example, certainly suggest that toluenized $B$. subtilis cells support DNA replication rather than repair synthesis, but Brown's findings raise new doubts about that. If Brown is right, toluenized cells may have to be added to the scrap heap of bacterial preparations which, although they make DNA in vitro, do not support chromosomal replication identical to that occurring in intact cells.

\section{ANTIQUITIES \\ Fooling the Experts}

from our Archaeology Correspondent

New thermoluminescence work on supposedly ancient ceramic objects, all recently acquired by museums and collectors, shows how successfully forgers and fakers are taking in their clients. Two studies undertaken at the Research Laboratory for Archaeology and the History of Art at the University of Oxford indicate not only the effectiveness of the thermoluminescence method, but the great difficulty that experts have in distinguishing genuine objects from false ones simply by their appearance.

The first study, by M. J. Aitken, P. R. S. Moorey and P. J. Ucko (Archaeometry, 13, 89; 1971), exposes as fakes no fewer than forty-eight out of sixty-six bowls, figurines and anthropomorphic vessels, which have supposedly come from illicit excavations at the prehistoric site of Hacilar in Turkey. Since the successful excavations there by James
Mellaart in 1957 and subsequent years (Excavations at Hacilar, I and II: Edinburgh Univ. Press; 1970), the attractively painted pottery and baked clay figurines discovered have rightly had an important place in the early history of art. Similar objects from illicit excavations have fetched up to $£ 3,000$ on the antiquities market.

Thermoluminescence glow curves obtained by Aitken show that most of the specimens examined emitted very little light on heating. The thermoluminescence observed is proportional to the radiation which the clay has undergone since it was fired-the radiation originates chiefly from radioactive isotopes in the clay or in the soil in which the object was buried - and hence upon its age since firing. Forty-eight out of sixty-six objects were evidently recently fired. The remote possibility that genuine ancient pieces had undergone heating in recent times to consolidate them, thereby removing the accumulated thermoluminescence, was checked by S. J. Fleming and D. Stone-

\title{
Streptovaricins Suppress Oncogenicity
}

LAST March Brockman and his colleagues reported in Nature (230, 249 ; 1971) that the streptovaricins - a family of antibiotics, the structure of which is similar to that of the rifamycins-inhibit the activity of reverse transcriptase in mouse leukaemia virus particles. At concentrations of $40 \mu \mathrm{g} / \mathrm{ml}$. the enzyme's activity was inhibited by 75 per cent. In next Wednesday's Nature New Biology Brockman's group describe their latest experiments with these drugs which show that streptovaricins not only inhibit the transformation by mouse sarcoma virus of mouse 3T3 cells growing in culture, but also selectively inhibit the progress of erythroblastic leukaemia and spleen enlargement induced in mice by Rauscher leukaemia virus. Their work thus suggests that streptovaricins might become useful chemotherapeutic agents for the treatment of cancer.

At concentrations which do not slow down the rate of cell division, those streptovaricins which inhibit reverse transcriptase also block by from 25 to 50 per cent the induction of foci of transformed cells by mouse sarcoma virus. This fact, together with the finding that the antibiotics are ineffective $24 \mathrm{~h}$ after infection, suggests that the inhibition of transformation results from the inhibition of reverse transcriptase activity. Moreover the inhibition of transformation by streptovaricins was enhanced if the cells were exposed simultaneously to interferon, which Brockman et al. suggest specifically inhibits the translation of viral messenger RNAs.

But inhibiting transformation in vitro is one thing ; inhibiting the induction of a cancer in an intact animal is another. Can streptovaricin alter the course of events after mice are infected with a virus such as Rauscher leukaemia virus? According to Brockman and his colleagues it can. They find that mice fed streptovaricin in their food such that the concentration of the drug in their serum is from 1 to $3 \mu \mathrm{g} / \mathrm{ml}$. are protected to a significant extent against splenomegaly induced by Rauscher murine leukaemia virus. The spleens of mice fed the drug before and throughout the infection are only about 50 per cent as large as those of mice given the virus but not the drug. Moreover when the drug is not given until 8 days after infection, when spleen enlargement is well under way, it can still significantly reduce further enlargement.

These findings, together with the observation that streptovaricin does not inhibit transformation in vitro if it is given $24 \mathrm{~h}$ after infection, lead Brockman's group to conclude that in vivo the drug is blocking secondary focus formation in the spleen. The drug does not, however, reduce the proliferation of normal haematopoietic cells, as judged by spleen focus counts, neither does it impair spleen enlargement in mice inoculated with the L1210 transplantable lymphoma cells.

In short, in mice the streptovaricins seem to block a virus-induced oncogenetic event rather than affecting the proliferation of malignant cells. In the intact animal it may therefore be acting as an inhibitor of tumour virus reverse transcriptase. 